\title{
Faktor-Faktor yang Mempengaruhi Penyerapan Tenaga Kerja Pada Sektor Pertanian di Sumatera Utara
}

\section{The Factors That Influence Labor Absorption in Agriculture Sector in North Sumatera}

\author{
Andika Pramana Hardai Hasibuan1), Rahmanta Ginting2), Ihsan Effendi3)
}

1) Program Studi Magister Agribisnis, Pascasarjana, Universitas Medan Area, Indonesia

2)Departemen Agribisnis, Fakultas Pertanian, Universitas Sumatera Utara, Indonesia

3) Magister Agribisnis, Pascasarjana Universitas Medan Area, Indonesia

\begin{abstract}
Abstrak
Penelitian ini bertujuan untuk mengetahui faktor-faktor apa saja yang mempengaruhi penyerapan tenaga kerja di sektor pertanian. Metode penelitian yang digunakan adalah menganalisa deskriptif dengan pendekatan kuantitatif menggunakan persamaan regresi berganda dengan menggunakan software Eviews seri 7. Penelitian ini menggunakan data time series dari tahun 1986 hingga 2016. Variabel dependen yang digunakan adalah serapan tenaga kerja di sektor pertanian di Sumatera Utara sedangkan variabel independen yang digunakan adalah inflasi, investasi dan Upah Minimum Provinsi. Hasil penelitian menunjukkan bahwa variabel inflasi dan investasi berpengaruh singifikan positif terhadap penyerapan tenaga kerja. Upah minimum provinsi memberikan pengaruh negatif terhadap penyerapan tenaga kerja pada sektor pertanian di Provinsi Sumatera Utara.

Kata Kunci: Inflasi, Investasi, Upah Minimum Provinsi, Tenaga Kerja, Sektor Pertanian.
\end{abstract}

\begin{abstract}
This study aims to determine what factors influence labor absorption in agriculture sector. The research method used is descriptive analysis with a quantitative approach using multiple regression equations using series 7 Eviews software. This research used time series data from 1986 until 2016. This research using labor absorption as dependent variable and the independent variables are inflation, investation, and provincial minimum wage. The results of the study show that inflation and investment variables have a significant positive effect on employment. The provincial minimum wage has a negative effect on employment in the agricultural sector in North Sumatra Province. Keywords : Inflation, Investation, Province Minimum Wage, Labor, Agriculture Sector
\end{abstract}

How to Cite: Hasibuan, A.P.H., R. Ginting dan I. Effendi. (2019). Faktor-Faktor yang Mempengaruhi Penyerapan Tenaga Kerja pada Sektor Pertanian di Sumatra Utara. Jurnal Ilmiah Magister Agribisnis, 1(1) 2019: 10-16. 


\section{PENDAHULUAN}

Pertumbuhan Ekonomi Provinsi Sumatera Utara yang diukur berdasarkan kenaikan Produk Domestik Regional Bruto (PDRB) Atas Dasar Harga Berlaku (ADHB) pada tahun 2016 sebesar Rp 628.394,16 milyar yang tergolong mengalami peningkatan setiap tahunnya. Sektor pertanian sebagai kontributor utama dengan peranan mencapai $(21,65 \%)$. Selanjutnya sektor industri pengolahan $(19,98 \%)$, sektor perdagangan $(17,89 \%)$, sektor konstruksi $(13,40 \%)$ dan sektor-sektor lain memberikan total kontribusi sebesar 27,08\% (BPS, 2016).

Perekonomian di suatu wilayah juga dapat dilihat dari adanya tingkat inflasi yang menggambarkan stabilitas perkenomian atau kenaikan harga-harga barang yang berlaku di suatu wilayah tersebut. Berdasarkan teori permintaan, bila permintaan naik maka harga juga akan naik. Dengan naiknya harga barang disebut dengan inflasi maka produsen akan meningkatkan kapasitas produksinya salah satunya dengan menambah tenaga kerja (tenaga kerja merupakan input yang dapat meningkatkan output). Dengan demikian jumlah pengangguran akan berkurang bila produsen melakukan penambahan jumlah tenaga kerja (Sukirno, 2004).

Negara berkembang yang memiliki jumlah penduduk yang tinggi, pembangunan ekonomi yang baik tidak hanya diikuti oleh tingginya angka pertumbuhan ekonomi akan tetapi diikuti juga oleh semakin berkurangnya tingkat pengangguran di negara tersebut. Persentase jumlah pengangguran di Provinsi Sumatera Utara secara umum mengalami penurunan yaitu 6,23\% tahun 2014, 6,71\% tahun 2015 dan menjadi 5,84\% di tahun 2016 (BPS, 2016). Lapangan pekerjaan yang memberikan kontribusi besar dalam penyerapan tenaga kerja dan mengurangi tingkat pengangguran tersebut adalah sektor pertanian sebesar $44,50 \%$ dan sisanya bersumber dari sektor lainnya. Dengan demikian permasalahan pengangguran di Provinsi Sumatera Utara dapat diturunkan dengan adanya pengembangan sektor pertanian yang juga memberikan kontribusi paling besar terhadap perekonomian .

Sektor pertanian yang dikelola dengan baik akan mampu memberikan pengaruh besar dalam hal meningkatkan perekonomian, pendapatan dan penyerapan tenaga kerja. Khususnya dalam hal penyerapan tenaga kerja, sektor pertanian tidak terlepas dari adanya peranan pemerintah yang mendukung dalam perkembangan sektor tersebut. Antara lain dengan kebijakan pemerintah membantu dalam merealisasikan investasi atau penanaman modal baik dari pihak asing maupun dalam negeri yang akan menjadi pasokan modal bagi sektor pertanian mengembangkan kegiatan usahanya. Dengan adanya investasi yang masuk pada sektor pertanian, akan dimanfaatkan untuk perkembangan kegiatan usaha seperti perluasan lahan dan menambah kapasitas produksi yang tentunya akan membutuhkan tenaga kerja sebagai penggerak utama dalam kegiatan usaha pertanian tersebut (Sukirno, 1997).

Peran pemerintah pada perkembangan sektor pertanian yang diharapkan dapat melakukan penyerapan tenaga kerja juga menetapkan besaran nilai dalam pemberian upah kepada tenaga kerja yang terdapat pada semua sektor khususnya dalam hal ini sektor pertanian. Teori Bentham menyatakan bahwa pemerintah memiliki tanggung jawab untuk membantu meningkatkan kesejahteraan warganya antara lain melalui 
berbagai kebijakan di bidang ekonomi dan sosial. Nilai upah yang diberikan kepada pekerja telah memiliki pedoman dari pihak pemerintah wilayah tersebut yang dikenal dengan sebutan Upah Minimum Provinsi/Kabupaten yang berlaku (Pressman, 2002). Namun dalam hal pemberian upah sering menjadi kontroversi dalam bidang ketenagakerjaan. Terkadang peningkatan upah minimum menjadi pertimbangan bagi pelaku usaha untuk melakukan penyerapan tenaga kerja. Karena pada dasarnya jika upah minimum Provinsi/Kabupaten naik, pihak pelaku usaha akan meminimalkan biaya operasionalnya untuk mengantisipasi pengeluaran biaya ditahun kedepannya dengan melakukan pengurangan tenaga kerja (Sumarsono, 2003).

Dengan adanya inflasi, investasi, dan kenaikan upah minimum Provinsi yang berlaku dapat mempengaruhi naik turunnya kemampuan sektor pertanian dalam menyerap tenaga kerja di Provinsi Sumatera. Penelitian ini dilakukan menggunakan data dari tahun 1986-2016. Berdasarkan penjelasan di atas, maka perumusan masalah dalam penelitian ini adalah bagaimana pengaruh inflasi, investasi, dan upah minimum provinsi terhadap penyerapan tenaga kerja pada sektor pertanian di Provinsi Sumatera Utara.

\section{METODE PENELITIAN}

Penelitian ini dilakukan di Provinsi Sumatera Utara, khususnya dalam ruang lingkup data sektor pertanian secara keseluruhan, meliputi data subsektor tanaman pangan, peternakan, perikanan, perkebunan dan kehutanan. Penelitian ini berbentuk analisa deskriptif dengan metode pendekatan kuantitatif. Penelitian ini menggunakan data sekunder yang diperoleh dari Badan Pusat Statistik dan Dinas Tenaga Kerja Provinsi Sumatera Utara dengan menggunakan data time series dari tahun 1986 sampai 2016. Variabel independen yang digunakan adalah data inflasi, investasi dan upah minimum provinsi sedangkan variabel dependennya adalah tenaga kerja di sektor pertanian. Analisis menggunakan regresi linear berganda dalam bentuk Logaritma Natural (Ln) dengan menggunakan bantuan program Eviews seri 7, berikut persamaan regresi yang digunakan :

$\operatorname{Ln} \mathrm{Y}=\mathrm{Ln} \beta_{0}+\beta_{1} \operatorname{Ln} X_{1}+\beta_{2} \operatorname{LnX} X_{2}+\beta_{3} \operatorname{Ln} X_{3}+\mathrm{e}$

Keterangan :

Y : Serapan tenaga kerja

$\mathrm{X}_{1}$ : Inflasi

$\mathrm{X}_{2}$ : Investasi

$\mathrm{X}_{3}$ : Upah Minimum Provinsi

E : error

$\beta_{0}$ : konstanta

$\beta_{1,2,3}$ : koefisien regresi

Selanjutnya dianalisa dengan intreprestasi koefisien output yang diperoleh, pengujian secara parsial, simultan dan koefisien determinasi serta pengujian asumsi klasik. 


\section{HASIL DAN PEMBAHASAN}

Berdasarkan data yang telah diperoleh menyatakan bahwa perkembangan inflasi di Provinsi Sumatera Utara dari tahun 1986 sampai dengan 2016 mengalami fluktuasi yang secara umum mengalami penurunan. Inflasi terbesar terjadi pada tahun 1998 yaitu sebesar $83,56 \%$ seiring dengan terjadinya krisis ekonomi yang melanda Indonesia secara nasional. Perkembangan investasi pada sektor pertanian di Provinsi Sumatera Utara juga berfluktuasi namun secara umum mengalami peningkatan dari tahun 1986 sampai dengan tahun 2015. Pasca krisis ekonomi yang terjadi di Indonesia, investasi yang masuk pada sektor pertanian di Provinsi Sumatera Utara meningkat cukup tinggi, yaitu sebesar Rp. 2.344.977,99 juta, dan sumber terbesar penanaman modal tersebut dilakukan oleh penanaman modal asing (PMA) yang masuk pada sektor pertanian, khususnya pada subsektor perkebunan. Perkembangan data upah minimum Provinsi secara umum stabil mengalami peningkatan setiap tahunnya. Dan untuk perkembangan data jumlah tenaga kerja pada sektor pertanian secara keseluruhan dari tahun 1986 sampai dengan tahun 2015 mengalami fluktuasi peningkatan sampai dengan tahun 2010, namun mengalami penurunan sampai dengan tahun 2015. Hal tersebut disebabkan semakin banyaknya para pekerja pada sektor pertanian yang beralih pekerjaan ke sektor industri dan perdagangan serta sektor lainnya yang juga berkembang di Provinsi Sumatera Utara.

Untuk mengetahui bagaimana pengaruh dari data perkembangan inflasi, investasi dan upah minimum Provinsi tersebut terhadap penyerapan tenaga kerja pada sektor pertanian di Provinsi Sumatera Utara, dilakukan analisis regresi berganda dengan bantuan program komputer Eviews 7, diperoleh hasil dengan persamaan dan data sebagai berikut :

Tabel 1. Hasil estimasi regresi berganda dengan program Eviews Versi 7

\begin{tabular}{|c|c|c|c|c|c|}
\hline \multicolumn{6}{|c|}{ Persamaan Regresi : } \\
\hline \multicolumn{6}{|c|}{$\operatorname{Ln} Y=\operatorname{Ln} \beta 0+\beta 1 \operatorname{LnX} 1+\beta 2 \operatorname{LnX} 2+\beta 3 \operatorname{LnX} 3+\mathbf{e}$} \\
\hline $\operatorname{Ln} Y=0,864$ &, $029 \operatorname{LnX} 1$ & $0,008 \operatorname{LnX} 2$ & 024LnX3 + & & \\
\hline Variable & t-statistic & Probability & F-statistic & $\begin{array}{l}\text { Probability } \\
\text { F-statistic }\end{array}$ & R-Squared \\
\hline X1 (Inflasi) & 2,143 & 0,041 & & & $\begin{array}{l}0,7843 \\
\text { atau }\end{array}$ \\
\hline X2 (Investasi) & 2,110 & 0,044 & 31,523 & 0,000 & $(78,43 \%)$ \\
\hline X3 (UMP) & $-2,240$ & 0,033 & & & \\
\hline
\end{tabular}

Sumber : Analisis data sekunder

Nilai koefisien dari variabel inflasi 0,029X1. Tanda koefisien positif tersebut menunjukkan adanya pengaruh positif dari inflasi terhadap penyerapan tenaga kerja pada sektor pertanian di Provinsi Sumatera Utara. Koefisien regresi sebesar 0,029 menjelaskan bahwa, apabila inflasi meningkat sebesar 10\% maka jumlah penyerapan tenaga kerja akan meningkat sebesar 0,29\% dari total tenaga kerja sebelumnya (ceteris paribus). Secara parsial atau secara individu variabel ini juga menunjukkan adanya pengaruh signifikan terhadap variabel penyerapan tenaga kerja. Nilai probability 0,041 
lebih kecil dari alpa 0,05 yang menyatakan bahwa variabel inflasi memiliki pengaruh positif dan signifikan terhadap penyerapan tenaga kerja pada tingkat kepercayaan $5 \%$. Sesuai dengan pernyataan Sukirno dalam bukunya pada tahun 2004 yang menyatakan bahwa dengan naiknya harga barang disebut dengan inflasi maka produsen akan meningkatkan kapasitas produksinya salah satunya dengan menambah tenaga kerja (tenaga kerja merupakan input yang dapat meningkatkan output). Kondisi kenaikan harga barang tersebut dimanfaatkan oleh produsen atau pelaku usaha pada sektor pertanian untuk lebih meningkatkan kuantitas produksinya dengan harapan agar dapat terjual pada kondisi harga yang tinggi untuk mendapatkan keuntungan yang maksimal. Dalam proses peningkatan produksi tersebut, produsen membutuhkan input atau faktor produksi sebagai penggerak utama dalam menghasilkan produksi, yaitu tenaga kerja. Dengan demikian, apabila inflasi meningkat yang menggambarkan harga-harga barang yang berlaku di pasar juga meningkat, para produsen atau pelaku usaha akan melakukan penyerapan tenaga kerja. Hasil penelitian terdahulu yang dilakukan oleh Dharma (2015) menunjukkan bahwa inflasi berpengaruh negatif terhadap penyerapan tenaga kerja, analisis dilakukan secara keseluruhan sektoral bidang usaha yang ada di Kota Samarinda (Secara Umum). Namun dalam penelitian ini analisis di fokuskan pada sektor pertanian di Provinsi Sumatera Utara, dan hasil yang diperoleh inflasi berpengaruh positif dan signifikan terhadap penyerapan tenaga kerja.

Nilai koefisien dari variabel investasi 0,008X2. Tanda koefisien yang positif untuk investasi menunjukkan adanya pengaruh positif dari investasi terhadap penyerapan tenaga kerja pada sektor pertanian di Provinsi Sumatera Utara. Koefisien regresi sebesar 0,008 menjelaskan bahwa, apabila investasi meningkat sebesar 10\% maka jumlah penyerapan tenaga kerja akan meningkat sebesar 0,08 orang dari total tenaga kerja sebelumnya (ceteris paribus). Secara parsial atau secara individu variabel investasi ini juga menunjukkan adanya pengaruh signifikan terhadap variabel penyerapan tenaga kerja. Nilai probability 0,044 lebih kecil dari alpa 0,05 yang menyatakan bahwa variabel investasi memiliki pengaruh positif dan signifikan terhadap penyerapan tenaga kerja pada tingkat kepercayaan 5\%. Didukung oleh pernyataan yang dikemukaan Sukirno (1997), dengan adanya investasi yang masuk pada sektor pertanian, akan dimanfaatkan untuk perkembangan kegiatan usaha seperti perluasan lahan dan menambah kapasitas produksi yang tentunya akan membutuhkan tenaga kerja sebagai penggerak utama dalam kegiatan usaha pertanian tersebut. Hasil penelitian ini mendukung hasil penelitian yang dilakukan oleh Sianturi (2009) yang memperoleh pengaruh positif dari investasi terhadap penyerapan tenaga kerja, namun penelitiannya dilakukan pada sektor industri di Provinsi Sumatera Utara.

Nilai koefisien dari variabel upah minimum Provinsi -0,024X3. Tanda koefisien yang negatif untuk upah minimum provinsi menunjukkan adanya pengaruh negatif dari upah minimum Provinsi terhadap penyerapan tenaga kerja pada sektor pertanian di Provinsi Sumatera Utara. Koefisien regresi upah minimum Provinsi sebesar -0,024 menjelaskan bahwa, apabila upah minimum Provinsi meningkat sebesar 10\% maka jumlah penyerapan tenaga kerja akan menurun sebesar 0,24 Orang dari total tenaga 
kerja sebelumnya. Namun secara parsial atau secara individu variabel UMP menunjukkan adanya pengaruh signifikan terhadap variabel penyerapan tenaga kerja. Nilai probability 0,033 lebih kecil dari alpa 0,05 yang menyatakan bahwa variabel UMP memiliki pengaruh negatif terhadap penyerapan tenaga kerja, akan tetapi pengaruhnya signifikan pada tingkat kepercayaan 5\%. Peningkatan upah minimum di Provinsi Sumatera Utara bagi masyarakat yang memiliki status pekerjaan merupakan peningkatan kesejahteraan dalam segi pendapatan yang diperoleh. Namun bagi pelaku usaha, peningkatan upah minimum akan menjadi pertimbangan untuk melakukan penyerapan tenaga kerja. Karena jika upah minimum Provinsi naik, pihak pelaku usaha akan meminimalkan biaya operasionalnya untuk mengantisipasi pengeluaran biaya ditahun kedepannya dengan tidak melakukan penyerapan tenaga kerja, bahkan melakukan pengurangan tenaga kerja. (Sumarsono, 2003). Pengaruh negatif upah minimun terhadap penyerapan tenaga kerja ini mendukung hasil penelitian yang dilakukan oleh Lubis (2010) dan Sulistiawaty (2012) yang memperoleh hasil bahwa upah minimum memberikan pengaruh negatif terhadap penyerapan tenaga kerja.

Berdasarkan hasil uji simultan atau secara serempak, menunjukkan bahwa model regresi ini memiliki nilai $\mathrm{F}$ hitung 31,523, yang signifikan pada derajat kepercayaan 95\%. Hal ini menjelaskan bahwa variabel-variabel independent inflasi, investasi dan upah minimum Provinsi secara bersama-sama memberi penjelasan terhadap variabel dependent penyerapan tenaga kerja.

Untuk pengujian koefisien determinasi, dari hasil regresi diperoleh nilai $\mathrm{R}^{2}$ sebesar 0,7843. Hal ini menjelaskan bahwa variabel-variabel independent diantaranya variabel inflasi, investasi dan upah minimum Provinsi yang dimasukkan dalam model memberi penjelasan mengenai variabel dependent yaitu penyerapan tenaga kerja sebesar 78,43\%. Sedangkan sisanya sebesar 21,57\% lagi dijelaskan oleh variabel lain yang tidak dimasukkan dalam model penelitian.

Pengujian asumsi klasik yang diperoleh juga menunjukkan bahwa model yang terbentuk dalam penelitian ini sudah terbebas dari penyimpangan uji asumsi klasik. Dengan rincian sebagai berikut :

Uji asumsi klasik linearitas dengan metode Ramsey Reset Test memiliki nilai Probability F hitung yang lebih besar dari alfa (tingkat kesalahan 5\%), yang menyatakan bahwa model penelitian telah memenuhi asumsi linearitas.

Uji asumsi klasik normalitas memiliki nilai Probability Jarque-Bera yang lebih besar dari alfa (tingkat kesalahan 5\%), yang menyatakan bahwa asumsi kenormalan terpenuhi.

Uji asumsi klasik autokorelasi dengan metode Breusch-Godfrey memiliki nilai Probability $\mathrm{F}$ hitung lebih besar dari alfa (tingkat kesalahan 5\%), yang menyatakan bahwa tidak terjadi autokorelasi dalam model penelitian.

Uji asumsi klasik multikolonieritas yang dilakukan dengan menggunakan nilai korelasi variabel independent diperoleh nilai yang tidak lebih dari 0,8 dan menggunakan nilai Centered VIF nilai juga tidak melebihi dari 10, menyatakan bahwa tidak terjadi multikolonieritas dalam model penelitian. 
Dan yang terakhir uji asumsi klasi heteroskedastisitas menggunakan metode uji Arch yang memiliki nilai Probability $\mathrm{F}$ hitung lebih besar dari alfa (tingkat kesalahan 5\%), menyatakan bahwa tidak terjadi heteroskedastisitas dalam model penelitian.

\section{SIMPULAN}

Dari hasil penelitian ini diketahui inflasi di Provinsi Sumatera Utara dari tahun 1986 sampai dengan tahun 2015 mengalami fluktuasi yang cenderung menurun, perkembangan inflasi tersebut memiliki pengaruh positif dan signifikan terhadap penyerapan tenaga kerja pada sektor pertanian. Perkembangan Investasi pada sektor pertanian di Provinsi Sumatera Utara mengalami fluktuasi yang secara umum mengalami peningkatan. Pengaruhnya positif dan signifikan terhadap penyerapan tenaga kerja. Sedangkan upah minimum di Provinsi Sumatera Utara cenderung stabil mengalami peningkatan, namun pengaruhnya negatif terhadap penyerapan tenaga kerja pada sektor pertanian. Besaran nilai pada kenaikan upah minimum menjadi pertimbangan bagi pelaku usaha untuk melakukan penyerapan tenaga kerja, dikarenakan harus meminimalkan biaya operasional ditahun kedepannya untuk menyesuaikan pemberian upah pada pekerja yang sudah ada. Bahkan pelaku usaha tersebut akan melakukan pengurangan tenaga kerja bila dianggap biaya operasional yang akan dikeluarkan ditahun kedepannya melebihi target biaya operasional yang telah ditentukan.

Untuk menjaga kestabilan nilai inflasi di Provinsi Sumatera Utara, pemerintah diharapkan dapat lebih fokus memperhatikan kondisi sistem pertanian, dimana sektor pertanian tersebut agar dapat menghasilkan produksinya yang stabil, agar tidak mengalami kekurangan ataupun kelebihan stok hasil produksi untuk dipasarkan, dimana kondisi tersebut berpengaruh terhadap harga yang akan ditawarkan. Dengan demikian nilai inflasi yang sebahagian bersumber dari harga barang produksi pertanian dapat terjaga kestabilannya. Sebab kondisi yang stabil tersebut merupakan peluang yang baik bagi pelaku usaha untuk meningkatkan hasil produksinya, dan secara langsung akan mempengaruhi penyerapan tenaga kerja yang digunakan sebagai faktor penggerak utama kegiatan usahanya. Pemerintah diharapkan juga dapat terus memperbaiki iklim investasi pada sektor pertanian di Provinsi Sumatera Utara untuk menarik minat para investor melakukan investasi dan juga mengoptimalkan alokasi penggunan investasi tersebut pada hal yang dapat meningkatkan penyerapan tenaga kerja pada sektor pertanian di Provinsi Sumatera.

\section{DAFTAR PUSTAKA}

BPS 1986. Sumatera Utara Dalam Angka 1986. Badan Pusat Statistik Sumatera Utara, Medan. BPS 1993. Sumatera Utara Dalam Angka 2015. Badan Pusat Statistik Sumatera Utara, Medan. BPS 2015. Sumatera Utara Dalam Angka 2015. Badan Pusat Statistik Sumatera Utara, Medan. BPS 2016. Sumatera Utara Dalam Angka 2016. Badan Pusat Statistik Sumatera Utara, Medan. Dharma, Bayu Dwi, 2015. Pengaruh investasi dan inflasi terhadap kesempatan kerja melalui pertumbuhan ekonomi di Kota Samarinda. Jurnal Kinerja Fakultas Ekonomi dan Bisnis Universitas Mualwarman. 
Lubis, Mitra Musika, 2010. Analisis faktor-faktor yang mempengaruhi penyerapan tenaga kerja Sektor pertanian di Sumatera Utara. Tesis Sekolah Pascasarjana Universitas Sumatera Utara.

Pressman, Steven, 2002. Lima Puluh Pemikir Ekonomi Dunia. Jakarta: PT. Raja Grafindo Persada.

Sianturi, Antoni, 2009. Pengaruh investasi dan konsumsi terhadap penyerapan tenaga kerja pada sektor industri di Sumatera Utara. Departemen Ekonomi Pembangunan. Universitas Sumatera Utara.

Sukirno, S, 1997. Makro Ekonomi. Teori Pengantar, Edisi 3. PT Raja Grafindo Persada: Jakarta.

Sukirno, S, 2004. Makro Ekonomi. Teori Pengantar, Edisi 3. PT Raja Grafindo Persada: Jakarta.

Sumarsono, Sonny , 2003. Ekonomi Sumber Daya Manusia, Teori dan Kebijakan Publik. Yogyakarta: Graha Ilmu.

Sulistiawaty, 2012. Pengaruh upah minimum terhadap penyerapan tenaga kerja dan kesejahteraan masyarakat di Provinsi di Indonesia. Jurnal Fakultas Ekonomi. Universitas Tanjungpura. Pontianak. 